Janette Vardy, Sydney Medical School, University of Sydney, Sydney, and Concord Cancer Centre, Concord; Meera Agar, Braeside Hospital, Hammond Care, Prairiewood, and South West Sydney Clinical School, University of New South Wales, Liverpool, New South Wales, Australia.

Published online ahead of print at www.jco.org on May 5, 2014

Authors' disclosures of potential conflicts of interest and author contributions are found at the end of this article.

Corresponding author: Janette Vardy, MD, Concord Cancer Centre, Concord Repatriation General Hospital, Hospital Rd, Concord, New South Wales, 2137, Australia; e-mail: janette.vardy@ sydney.edu.au.

(C) 2014 by American Society of Clinica Oncology

0732-183X/14/3216w-1677w/\$20.00 DOI: 10.1200/JCO.2013.52.8356

\title{
Nonopioid Drugs in the Treatment of Cancer Pain
}

Janette Vardy and Meera Agar

$$
\begin{array}{llllllll}
\text { A } & \text { B } & \text { S } & \text { T } & \text { R } & \text { A } & \text { C } & \text { T }
\end{array}
$$

The WHO analgesic ladder for the treatment of cancer pain provides a three-step sequential approach for analgesic administration based on pain severity that has global applicability. Nonopioids were recommended for mild pain, with the addition of mild opioids for moderate pain and strong opioids for severe pain. Here, we review the evidence for the use of nonopioid analgesic agents in patients with cancer and describe the mode of action of the main drug classes. Evidence supports the use of anti-inflammatory drugs such as acetaminophen/paracetamol and nonsteroidal anti-inflammatory drugs (NSAIDs) for mild cancer pain. Adding an NSAID to an opioid for stronger cancer pain is efficacious, but the risk of long-term adverse effects has not been quantified. There is limited evidence to support using acetaminophen with stronger opioids. Corticosteroids have a specific role in spinal cord compression and brain metastases, where improved analgesia is a secondary benefit. There is limited evidence for adding corticosteroids to stronger opioids when pain control is the primary objective. Systematic reviews suggest a role for antidepressant and anticonvulsant medications for neuropathic pain, but there are methodologic issues with the available studies. Bisphosphonates improve pain in patients with bony metastases in some tumor types. Denosumab may delay worsening of pain compared with bisphosphonates. Larger studies of longer duration are required to address outstanding questions concerning the use of nonopioid analgesia for stronger cancer pain.

J Clin Oncol 32:1677-1690. (c) 2014 by American Society of Clinical Oncology

\section{INTRODUCTION}

Up to $90 \%$ of patients with cancer experience pain at some stage of their cancer journey, with a third rating the intensity of their pain as moderate to severe, ${ }^{1-3}$ and up to half being undertreated. ${ }^{1,4,5}$ The WHO analgesic ladder, which provides guidelines for the treatment of cancer pain, was published in 1986 and updated in $1996 .^{6}$ The guidelines recommend a sequential three-step approach for analgesic administration based on pain severity, with nonopioids for mild pain, weak opioids for moderate pain, and strong opioids for severe pain. In addition to drug selection based on the severity of the pain and individualized for the patient, recommendations include the use of oral medications whenever possible, with fixed scheduled dosing according to the pharmacokinetics of the drug rather than on demand and regular assessment and re-evaluation of the pain. It is recommended that the drugs used in step 1 be continued as opioids are added. The rationale for adding a nonopioid to an opioid is to add a drug with a different mechanism of action with the aim of improving analgesic control and/or reducing opioid requirements and minimizing opioid adverse effects. ${ }^{7}$

When the WHO guidelines were developed to address the issue of undertreated pain, there was limited evidence to inform them. Rather, they were developed to provide a framework to guide international policy for the treatment of cancer pain with pain relief that was affordable and readily accessible globally. Despite controversies about whether the second step should be omitted and whether nonopioid analgesic agents should be continued once an opioid is required, the WHO analgesic ladder remains the mainstay of management of cancer pain. ${ }^{8}$ Individual studies and systematic reviews that have evaluated the WHO guidelines have shown that they can control cancer pain in $45 \%$ to $100 \%$ of patients. ${ }^{9-11}$

The most common nonopioid agents used to treat cancer pain include acetaminophen/paracetamol; anti-inflammatory agents such as nonsteroidal anti-inflammatory drugs (NSAIDs) and corticosteroids; antineuropathic agents, which include tricyclic antidepressants and anticonvulsants; and bisphosphonates. The mode of action of each drug is outlined in Table 1, and the major studies that have evaluated their use in people with cancer are outlined in Tables 2 to 6 .

\section{ACETAMINOPHEN/PARACETAMOL.}

Acetaminophen (known in some countries as paracetamol) is an inexpensive analgesic that is used globally. Although it was developed over a hundred years 


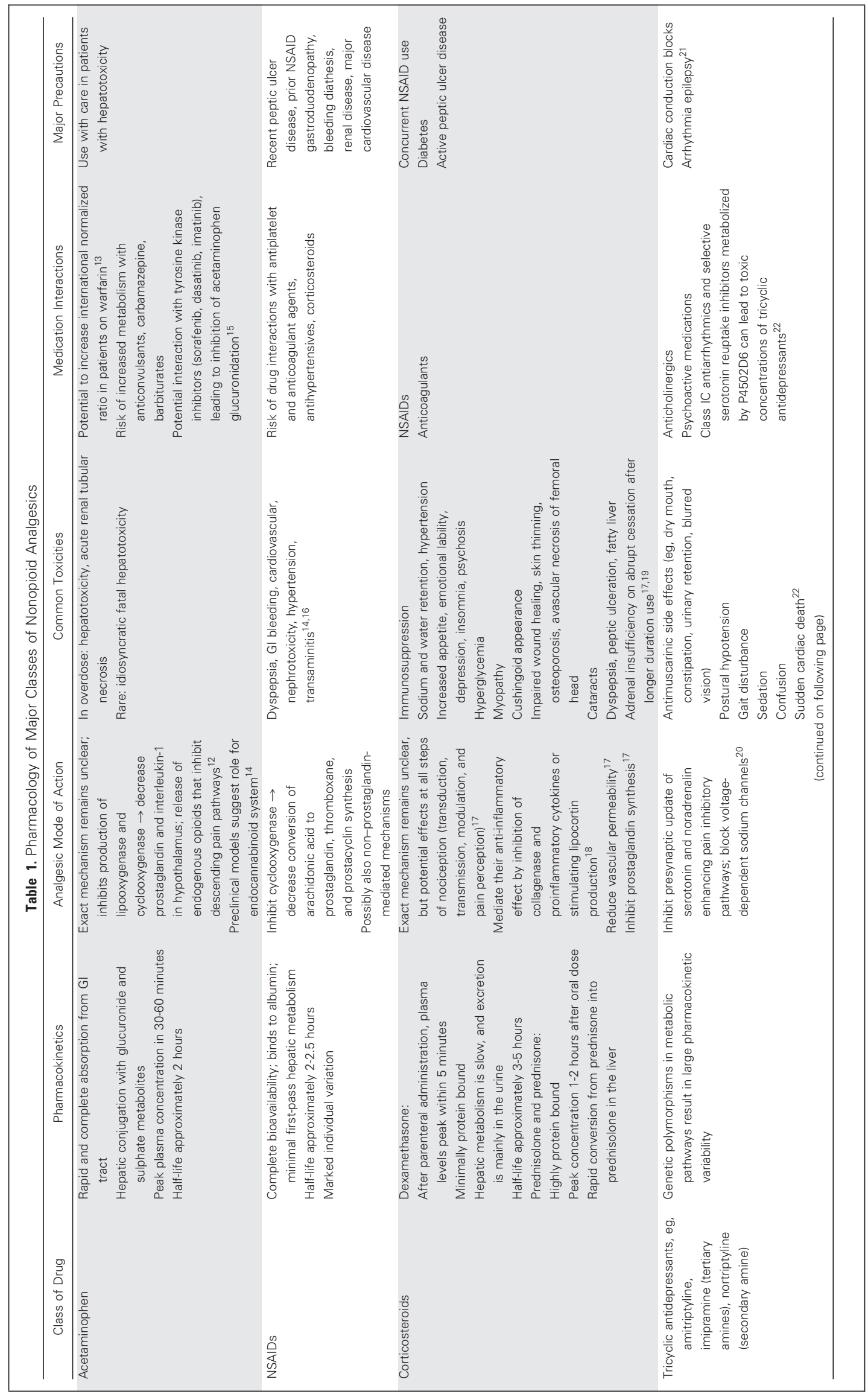




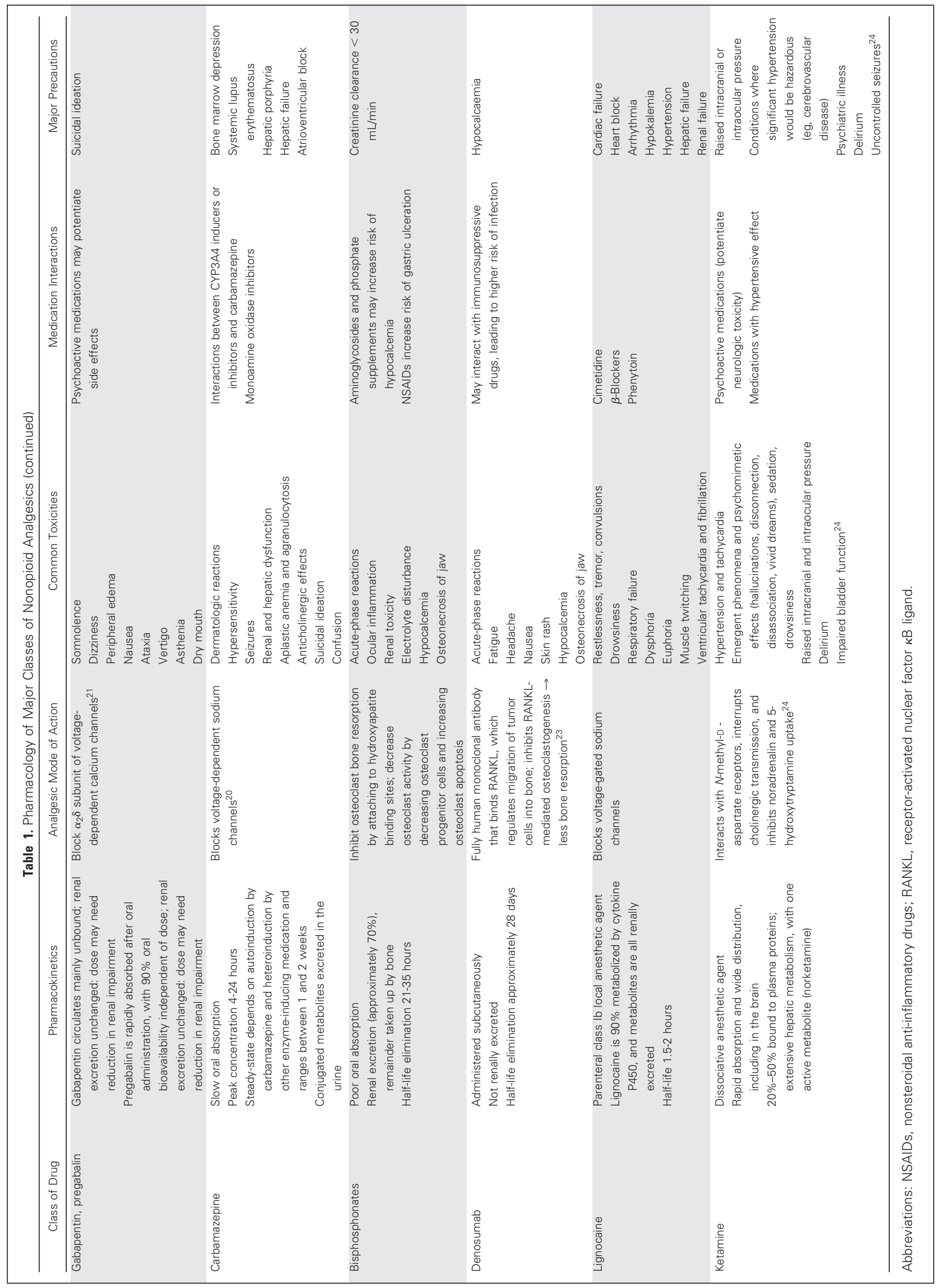


ago, its mode of action for pain relief has not been fully elucidated. It is sometimes classified as an NSAID, but its mechanism of action is not the same. ${ }^{25}$ Acetaminophen is well tolerated with a good safety profile at therapeutic doses. In overdose, hepatotoxicity and acute renal tubular necrosis can occur. Patients may be at higher risk of hepatotoxicity after starvation, fasting, or chronic alcohol abuse, but hepatic toxicity is rare in doses less than $8 \mathrm{~g}$ daily, even in patients with chronic liver disease. ${ }^{20,26}$ Serious hypersensitivity reactions to acetaminophen are extremely rare (Table 2 ).

\section{Acetaminophen for Acute Pain}

Systemic reviews and meta-analyses have shown that acetaminophen is more effective than placebo for acute postoperative pain. ${ }^{33-35}$ The optimal dose of acetaminophen remains uncertain. A Cochrane review of 51 studies including 5,762 postoperative participants and using an end point of $50 \%$ total pain relief found that a single dose of acetaminophen was significantly more effective than placebo, with a number needed to treat of 3.5 patients ( $95 \%$ CI, 2.7 to 4.8 patients) for $500 \mathrm{mg}$ of acetaminophen, 4.6 patients (95\% CI, 3.9 to 5.5 patients) for 600 to $650 \mathrm{mg}$, and 3.6 patients ( $95 \%$ CI, 3.4 to 4.0 patients) for 975 to $1,000 \mathrm{mg} .{ }^{33}$ There was no difference in adverse effects in the acetaminophen arms compared with placebo. ${ }^{33}$ Another Cochrane review comprising 20 studies and 2,641 patients evaluated oxycodone with and without acetaminophen for acute postoperative pain; the number needed to treat for oxycodone $15 \mathrm{mg}$ was 4.6 patients (95\% CI, 2.9 to 11 patients) compared with 2.7 patients ( $95 \%$ CI, 2.4 to 3.1 patients) for oxycodone $10 \mathrm{mg}$ and acetaminophen $650 \mathrm{mg}$. ${ }^{36}$

\section{Acetaminophen for Patients With Cancer}

There is good evidence that acetaminophen is effective for treating mild cancer pain. ${ }^{37}$ There is limited evidence for adding acetaminophen to an opioid, and practice varies globally; patients in Europe and Australasia generally remain on acetaminophen once opioids are required, but in North America, acetaminophen is generally discontinued once strong opioids are initiated. A systematic review evaluating acetaminophen in addition to opioids in five small randomized controlled trials (RCTs) involving 200 patients with cancer found no benefit to adding acetaminophen in four of the five studies. ${ }^{38}$ The positive study used a cross-over design. ${ }^{28}$ Patients reported a modest improvement in pain and overall well-being while on acetaminophen ( 1 g every 4 hours five times a day), with a nonsignificant preference for analgesic control during the period they were on acetaminophen. ${ }^{28}$ A recent RCT evaluated the efficacy of oxycodone (5 mg)/acetaminophen (325 mg) compared with placebo every 6 hours for 3 days for pain caused by bone metastases in 246 patients already on opioids. ${ }^{32}$ Although the oxycodone/acetaminophen group had improved pain relief, less breakthrough pain, and reduced need for rescue pain relief, the study design does not allow the relative contribution of each agent in the combination to be determined.

\section{NSAIDS}

NSAIDs are a heterogeneous group of drugs that inhibit cyclooxygenase (COX), leading to a reduction of the conversion of arachidonic acid to thromboxane $\mathrm{A}_{2}$ and prostaglandin synthesis (Table 1). ${ }^{39}$ There are two main forms of COX-COX-1 (including a variant known as COX-3) and COX-2. Although COX-1 is present in most tissues, COX-2 is mainly expressed in inflamed tissue. ${ }^{39,40}$ Most NSAIDs are nonselective inhibitors of COX-1 and COX-2, but newer agents such as celecoxib have much greater affinity for the COX-2 isoform. ${ }^{40}$ The selective COX-2 inhibitors are substantially more expensive than the older nonselective agents.

\section{Adverse Effects}

The toxicity profile for NSAIDs includes GI and cardiovascular effects, hepatotoxicity, and nephrotoxicity, including renal failure caused by renal vasoconstriction, hypertension, and electrolyte disturbances. $^{16,41}$ The risk of toxicity is increased with higher doses of NSAIDs and in those with comorbidities and the elderly. Patients with a history of GI bleeding, an NSAID-related ulcer, Helicobacter pylori infection, renal or hepatic impairment, or chronic heart failure are at increased risk of serious toxicity. Concomitant use of an NSAID with antiplatelet or anticoagulant agents, antihypertensives, glucocorticoids, or diuretics has an additive risk of hemorrhage or renal hypoperfusion. Prior treatment of $H$ pylori or concomitant use of a gastroprotectant agent (eg, a proton pump inhibitor) may reduce GI toxicity in those at higher risk. ${ }^{42}$ Selective COX-2 inhibitors cause less GI toxicity than nonselective COX-1 and COX-2 inhibitors, ${ }^{41}$ but several large studies have shown an increase in cardiovascular toxicity, including myocardial infarction and stroke, with the selective COX-2 inhibitor rofecoxib. ${ }^{43,44}$ This is thought to be a result of a prothrombotic effect. Some selective COX-2 inhibitors were withdrawn from the market in 2004 and 2005 because of this toxicity. ${ }^{44}$ Celecoxib is one of the main drugs in this class still in common usage.

\section{NSAIDs in Patients With Cancer}

The maximum recommended single dose of an NSAID has been found to be equivalent in analgesic potency to approximately 5 to 10 mg of parenteral morphine. ${ }^{45,46}$ A meta-analysis of 25 studies in 1,545 patients with cancer found benefit in all eight studies comparing a single dose of an NSAID with placebo. ${ }^{46}$ No significant difference in analgesic efficacy was found in studies comparing an NSAID with an NSAID and a weak opioid, but studies were difficult to compare because of heterogeneity (Table 3 ).

A Cochrane review found seven studies that compared an NSAID (excluding acetaminophen) with placebo for cancer pain. ${ }^{54}$ All studies reported improved efficacy for the NSAID, with no difference in adverse effects, but all were single-dose studies. Thirteen studies compared different NSAIDs, but there was no convincing evidence of benefit for one NSAID over another. Of the 10 studies that compared an NSAID with an opioid, four found the NSAID to be more effective, whereas two studies showed they were less beneficial. Metaanalyses of four of the studies found a lack of significant difference in pain relief but more adverse events in the opioid groups (odds ratio, $0.38 ; 95 \%$ CI, 0.15 to 0.97$){ }^{45,55-57}$

\section{Use of an NSAID With an Opioid}

Eight studies compared an NSAID versus an NSAID combined with an opioid; four of these studies found that the NSAID/opioid combination gave marginally better pain relief. Meta-analysis of six of the studies showed no significant difference in adverse events. ${ }^{54}$ The studies used a mixture of weak and strong opioids, making comparison problematic.

Both the Cochrane review ${ }^{54}$ and a more recent systematic review incorporating additional studies ${ }^{38}$ showed a benefit to adding an 


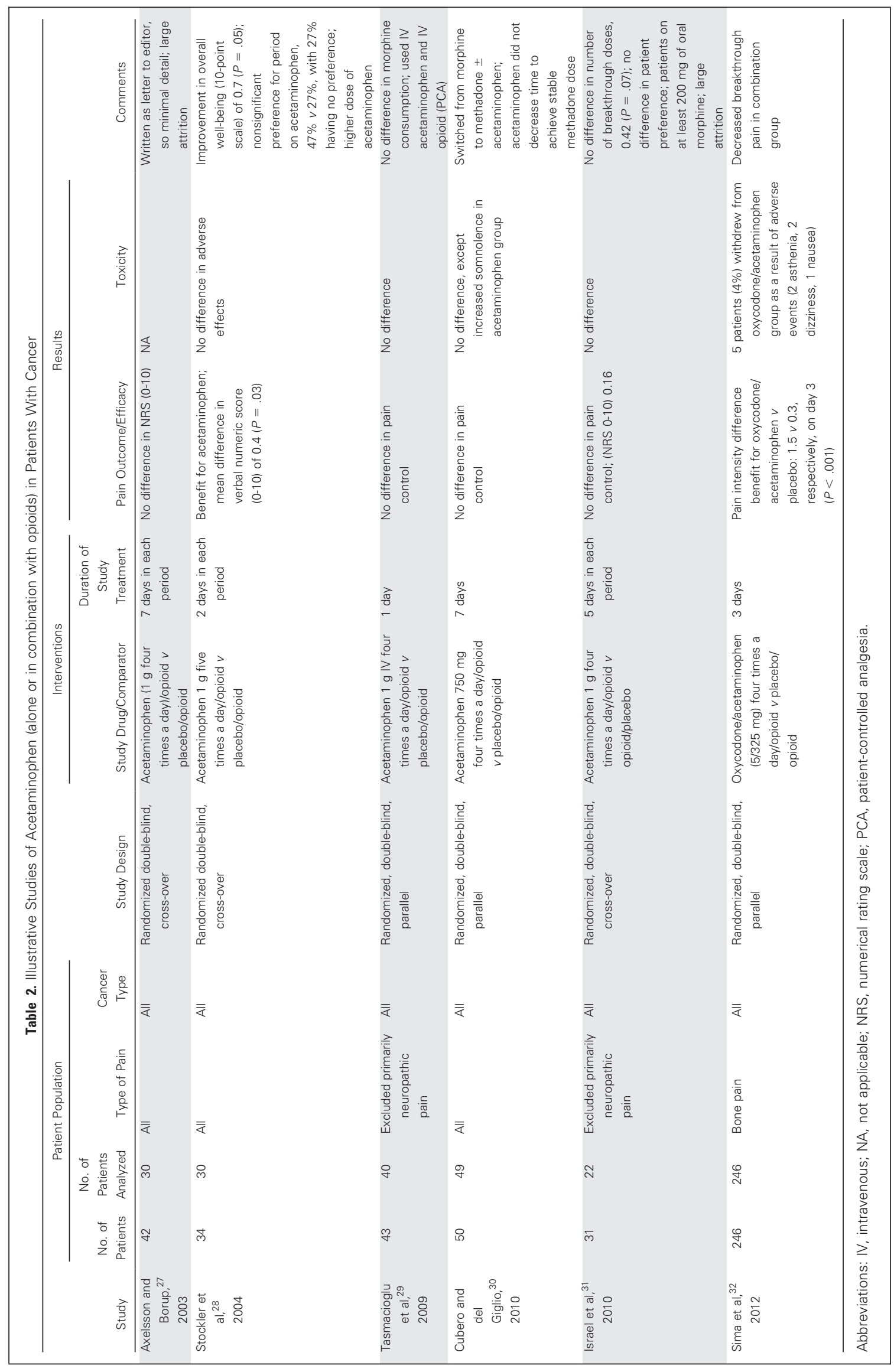




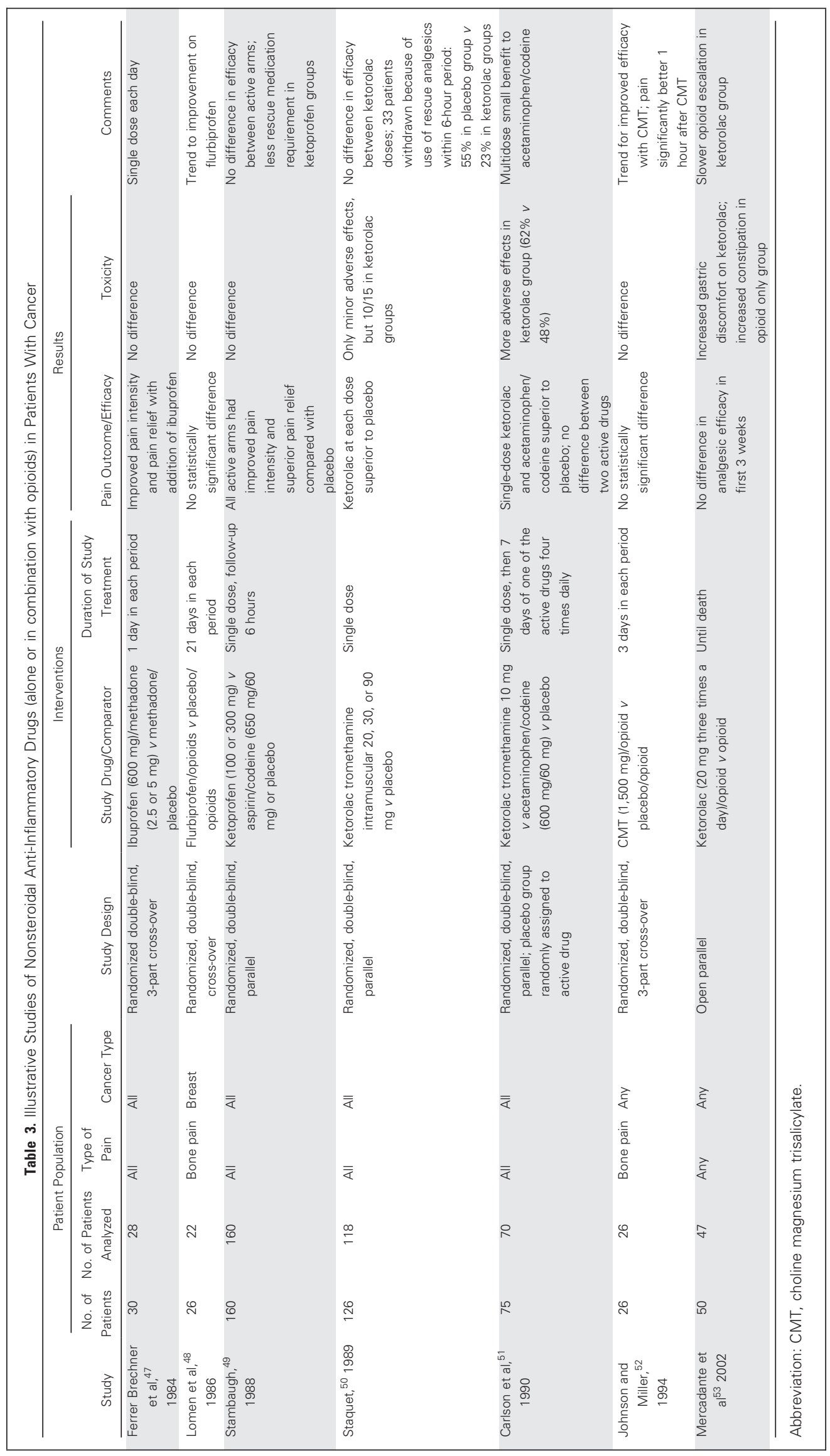


NSAID to a WHO step 3 opioid for cancer pain. Five of the seven studies found the addition of the NSAID to be efficacious, ${ }^{38}$ with three reporting improved pain with the addition of dipyrone ${ }^{58}$ or ibuprofen ${ }^{47,58 a}$ and two finding a decrease in opioid consumption with the addition of ketorolac ${ }^{53}$ or diclofenac. ${ }^{59}$ Six of the seven studies reported no significant differences in adverse effects between the groups, with one study finding more gastric discomfort in the NSAID plus opioid arm and more constipation in the opioid alone arm. ${ }^{53}$ There were no marked differences between the different NSAID drugs in efficacy, although individual responses to NSAIDs and their toxicity are highly variable.

Most of the acetaminophen and NSAID studies in patients with cancer had small sample sizes and were of short duration, and none included selective COX-2 inhibitors. Longer term efficacy and safety remain unknown, with prevalence and severity of toxicities not quantified in patients with cancer. Studies have not been adequately powered to determine whether NSAIDs or acetaminophen are more beneficial for certain types of cancer pain, although anecdotally, it is suggested that NSAIDs are more effective for pain associated with inflammation.

\section{CORTICOSTEROIDS}

\section{Mode of Action}

Inflammation has key roles in the pathophysiology of pain, and animal pain models suggest that corticosteroids can modulate pain perception. ${ }^{18}$ Proinflammatory cytokines are involved in the development of inflammatory and neuropathic pain, including CNS production from immune-competent glial cells. ${ }^{18}$ Endogenous neurosteroids in the CNS and peripheral nervous system modulate $\gamma$-aminobutyric acid, $N$-methyl-D-aspartate, and ATP/adenosine bisphosphate (P2X) receptors, all of which play crucial roles in pain regulation. ${ }^{17}$ Steroid receptors are present in several neural structures, which may allow steroids to modulate neural activity and plasticity. ${ }^{17}$ Sex steroids may also play a role, with testosterone exerting an analgesic effect and estrogens exerting both hyperalgesic and analgesic effects. ${ }^{17}$

\section{Adverse Effects}

Corticosteroids have multiple effects and lead to a wide range of potential short- and long-term adverse effects. ${ }^{19}$ These include effects on the stress and immune response, carbohydrate metabolism, protein catabolism, electrolyte regulation, and behavior. ${ }^{19}$

\section{Agents and Dose}

Commonly used corticosteroids are dexamethasone, methylprednisolone, betamethasone, prednisolone, and prednisone. ${ }^{18}$ Dexamethasone is prescribed most often; it causes less fluid retention than other corticosteroids because it has less mineralocorticoid effect. ${ }^{17,19}$ Corticosteroids are used with other analgesics in a broad range of clinical scenarios, in particular for management of bone and neuropathic pain. ${ }^{17}$ Corticosteroids are included at each step of the WHO analgesic ladder, when an anti-inflammatory effect is considered beneficial. ${ }^{17}$ They also have a role in specific clinical scenarios such as spinal cord compression, brain metastases, and bowel obstruction, ${ }^{60}$ where improved analgesia is a secondary benefit from the primary indication of reduction of peritumoral edema. ${ }^{19}$ There is no established dosing, and the studies that have been undertaken comparing dose effectiveness have explored outcomes other than pain. ${ }^{61}$

\section{Efficacy}

Despite corticosteroids being used widely to manage cancer pain, there is limited evidence for their efficacy. ${ }^{17}$ A recent systematic review demonstrated a paucity of studies and included four RCTs that explored the role of corticosteroids when added to standard pain management. ${ }^{18}$ One study demonstrated efficacy, and one study did not; the other two studies did not report pain or analgesic use adequately ${ }^{18}$ (Table 4).

\section{ANTIDEPRESSANTS AND ANTICONVULSANTS}

Neuropathic pain is defined by the International Association for the Study of Pain as pain caused by a lesion or disease of the somatosensory system. It is present in at least $35 \%$ to $40 \%$ of patients with cancer pain. ${ }^{20} \mathrm{Up}$ to $40 \%$ of survivors of cancer also report pain at 5 years after treatment that is often neuropathic in nature. ${ }^{22}$ Chronic pain that is related to treatment includes pain caused by postsurgical syndromes (eg, mastectomy, thoracotomy, postamputation); chemotherapyrelated painful peripheral neuropathy; avascular necrosis of the femoral or humeral head; and radiation-induced plexopathy, myelopathy, or proctitis.

Opioid analgesia is usually insufficient to achieve good control of neuropathic pain, and additional agents are required, mainly antidepressant and anticonvulsant medications. ${ }^{20,21}$ Neuropathic pain from cancer may not share pathophysiologic mechanisms with chronic nonmalignant causes, but a similar range of drugs is used. ${ }^{21}$ It is more common to try opioid analgesia alone before adding an adjuvant for neuropathic pain in North America, whereas European practice is to use combination therapy earlier. ${ }^{22}$

\section{Adverse Effects}

The choice of agent is often guided by the importance of potential adverse effects in an individual patient. For example, tricyclic antidepressants should be avoided if the patient is at risk of urinary retention. However, some clinicians choose agents based on characteristics of the pain. ${ }^{21}$ The agents are used mostly in combination with opioids, and adverse effects, in particular psychoactive adverse effects, can be synergistic.

\section{Agents and Dose}

There is a complex interplay between etiology, pathophysiology, and symptoms of neuropathic pain, and different pathophysiologic mechanisms can be responsible for similar symptoms. ${ }^{66}$ Therefore, if one agent is not effective, it is reasonable to try another agent that may mediate benefit through a different component of the involved pain pathways. When partial response is seen with one agent, some clinicians consider combination therapy with an agent from another class, but there are few data to indicate additional benefit from combination therapy or to guide the choice of combination. ${ }^{21}$ These medications are started usually at a low dose and titrated to a dose where effect is seen with acceptable toxicity. For example, tricyclic antidepressants are started at 10 to $25 \mathrm{mg}$ at bedtime and gradually increased every 3 to 7 days in 10- to 25-mg increments, up to doses of $150 \mathrm{mg} .{ }^{21}$ Gabapentin has an effective dose range of 100 to $3,600 \mathrm{mg}$ but is commenced in low doses of 100 to $300 \mathrm{mg}$ at night. ${ }^{21}$ Pregabalin doses range from 25 to $600 \mathrm{mg}$, commencing with 25 to $75 \mathrm{mg}$ at night. ${ }^{21}$ Available data suggest that adjuvants improve pain control within 4 to 8 days when 


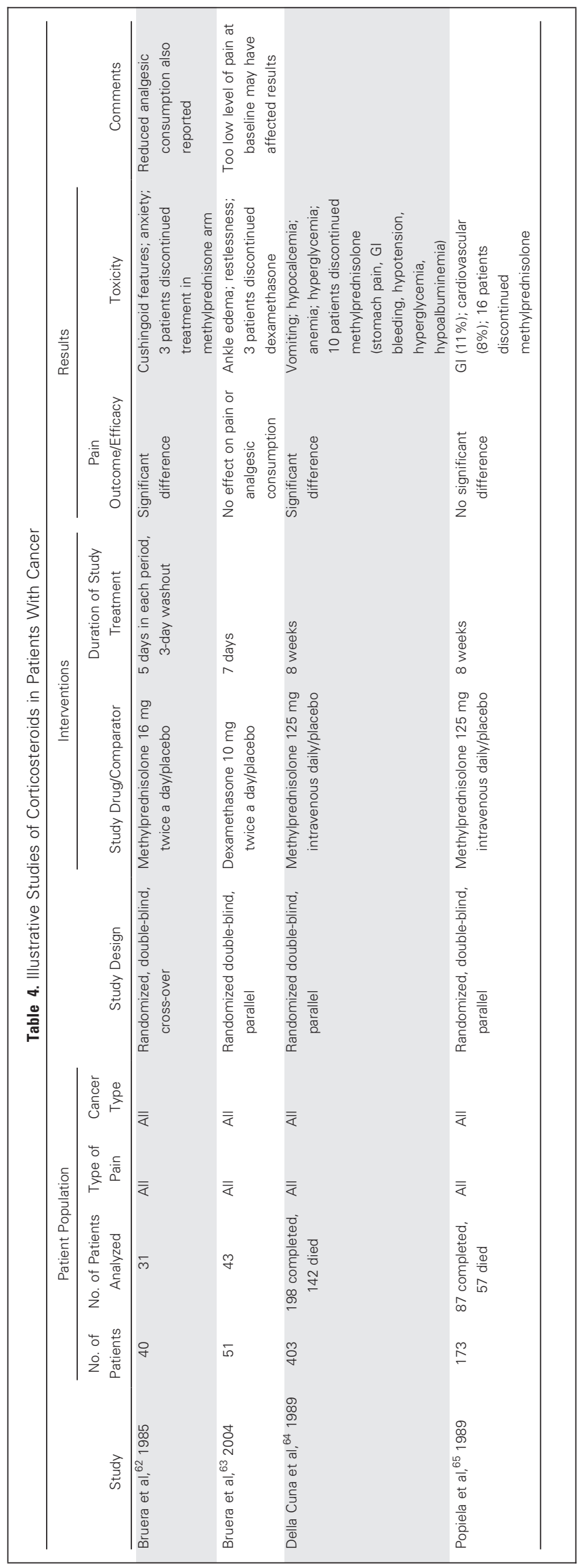


added to opioids for cancer pain. ${ }^{20}$ The doses used in the randomized studies are listed in Table 5.

\section{Efficacy}

There have been two recent reviews (one systematic) exploring the role of pharmacologic therapy of neuropathic cancer pain and another systematic review of the role of antiepileptic or antidepressants added to opioids for cancer pain..$^{20,21,67}$ These reviews support a beneficial effect for antidepressants and anticonvulsants in the treatment of both mixed-type and neuropathic cancer pain, but there are methodologic issues with the included studies. ${ }^{20,21}$ These include poorly defined primary outcome measures and varying doses of concomitant opioids. ${ }^{67}$ In several studies, CIs for outcomes in the intervention arm overlapped with those of the control arm, indicating a lack of significant difference, and it was not possible to make direct comparisons (number needed to treat, number needed to harm) because comparator arms include other active therapies as well as placebo. ${ }^{67}$ The effect size seen was much less than that in patients with noncancer neuropathic pain. ${ }^{20}$

There are limited data on treatment that is effective for neuropathic pain related to cancer treatment. A recent RCT explored the use of duloxetine $60 \mathrm{mg}$, an antidepressant from the selective serotonin and noradrenaline reuptake inhibitor class, for chemotherapyinduced painful peripheral neuropathy; it showed a mean decrease in average pain on an 11-point numeric rating scale of 1.06 (95\% CI, 0.72 to 1.4 ) in the duloxetine group versus 0.34 (95\% CI, 0.01 to $0.66 ; P=$ $.003)$ in the placebo group after 5 weeks of treatment. ${ }^{69}$

\section{BISPHOSPHONATES}

Bone metastases, a common source of pain, are caused by upregulated osteoclastic activity, leading to increased bone resorption. Bisphosphonates are selective inhibitors of osteoclastic bone resorption. There are two classes of bisphosphonates-the older simple bisphosphonates, such as etidronate and clodronate, and the more potent inhibitors of bone resorption, the nitrogen-containing bisphosphonates, which include pamidronate and zoledronate. Several meta-analyses have shown a decrease in skeletal-related events with bisphosphonates, and the evidence is strongest for breast cancer, ${ }^{74}$ prostate cancer, ${ }^{75}$ and multiple myeloma. ${ }^{76}$ A Cochrane review reported a reduction in skeletal-related events of $15 \%$ (risk ratio, 0.85 ; $95 \% \mathrm{CI}, 0.77$ to $0.94 ; P=.001$ ) in nine studies including 2,806 patients with breast cancer with bone metastases that compared a bisphosphonate with either placebo or no bisphosphonate. ${ }^{74}$ A significant improvement in bone pain was found after receiving a bisphosphonate in six of 11 studies that evaluated pain. A meta-analysis of eight studies comparing a bisphosphonate with placebo found minimal differences in adverse events between the two groups, but there was an increase in nausea and acute-phase reactions in the bisphosphonate arms. ${ }^{75}$ The risk of osteonecrosis of the jaw is estimated to be between $0.7 \%$ and $12 \%$ and is more likely to occur in patients with metastatic disease and with poor oral hygiene or after dental surgery ${ }^{74}$ (Table 5).

\section{DENOSUMAB}

Denosumab is a fully human monoclonal antibody against the cytokine receptor-activated nuclear $\kappa \mathrm{B}$ ligand (RANKL), which is in- volved in tumor cell migration and is a mediator of osteoclast differentiation and activation. ${ }^{23}$ Six RCTs in patients with bone metastases found a benefit for denosumab over zoledronic acid, pamidronate, or ibandronate in incidence (risk ratio, 0.84; 95\% CI, 0.80 to 0.88 ) and time to skeletal-related events, but no difference in overall survival, ${ }^{77}$ although subgroup analysis in one study suggested that patients with multiple myeloma may have increased mortality with denosumab. ${ }^{78}$ Total adverse events were similar, except for increased hypocalcemia and less nephrotoxicity with denosumab. One of the studies, in which pain was a secondary outcome, randomly assigned 2,046 women with breast cancer with bone metastases to denosumab or zoledronic acid. The study reported no meaningful difference in improvement in pain severity or time to improvement of pain between the groups, but there was less worsening of pain severity and less functional impairment secondary to pain and fewer patients required progression to strong opioid analgesics in the denosumab $\operatorname{arms}^{73}$ (Table 5).

These studies suggest that bisphosphonates are beneficial as an adjunct for pain control from bony metastases for some tumor types. Denosumab is more convenient than bisphosphonates but substantially more expensive.

\section{LIGNOCAINE (LIDOCAINE)}

Local anesthetics inhibit pain predominantly by blocking sodium channels and have shown efficacy in chronic nonmalignant neuropathic pain. ${ }^{21}$ Topical lignocaine has shown benefit in allodynia from postherpetic neuralgia. ${ }^{22}$ There are some uncontrolled and controlled studies of continuous subcutaneous infusion of lignocaine in cancer pain $^{79-81}$ (Table 6). However, these studies all have methodologic limitations, and the role of lignocaine needs to be substantiated in randomized placebo-controlled studies.

\section{KETAMINE}

The dissociative anesthetic ketamine has been used widely in the management of chronic cancer pain, usually in the setting of pain that is not controlled by opioids or opioids plus adjuvant analgesics. ${ }^{24}$ Its use had been mainly extrapolated from surgical settings, and evidence for benefit has come mainly from case series and uncontrolled studies in people with cancer (Table 6). However, in a recent RCT, there was no difference compared with placebo, pain type (neuropathic $v$ nociceptive) was not a predictor of response, and those receiving ketamine were more likely to experience adverse effects. ${ }^{24}$ This study was not powered to specifically compare differences in effect between neuropathic and nociceptive pain.

\section{CANNABINOIDS}

Some cultural groups have used cannabinoids for medicinal purposes for thousands of year. There is a lack of evidence for their efficacy for cancer pain, particularly compared with other agents, ${ }^{82}$ but trials are ongoing. 


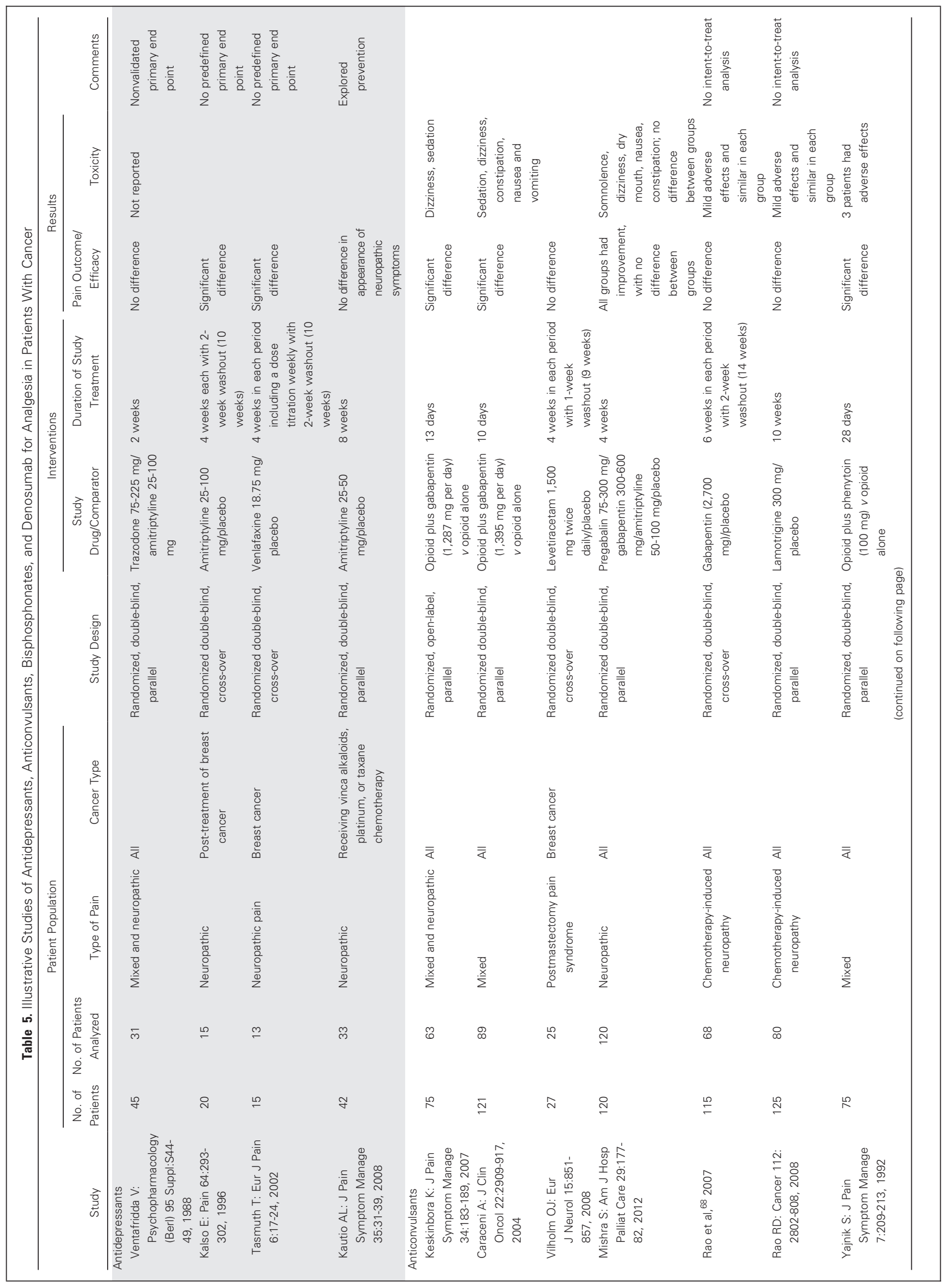




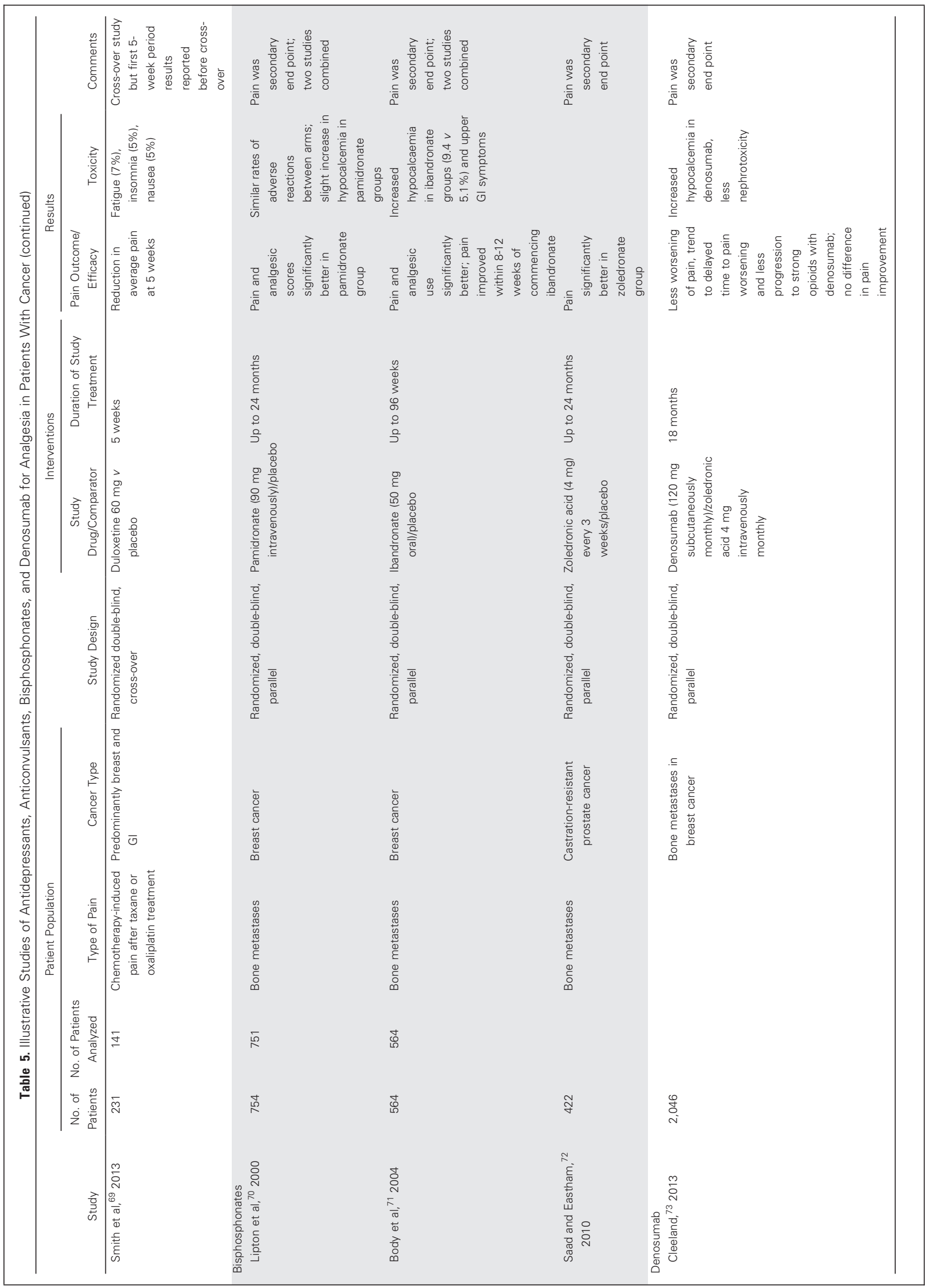




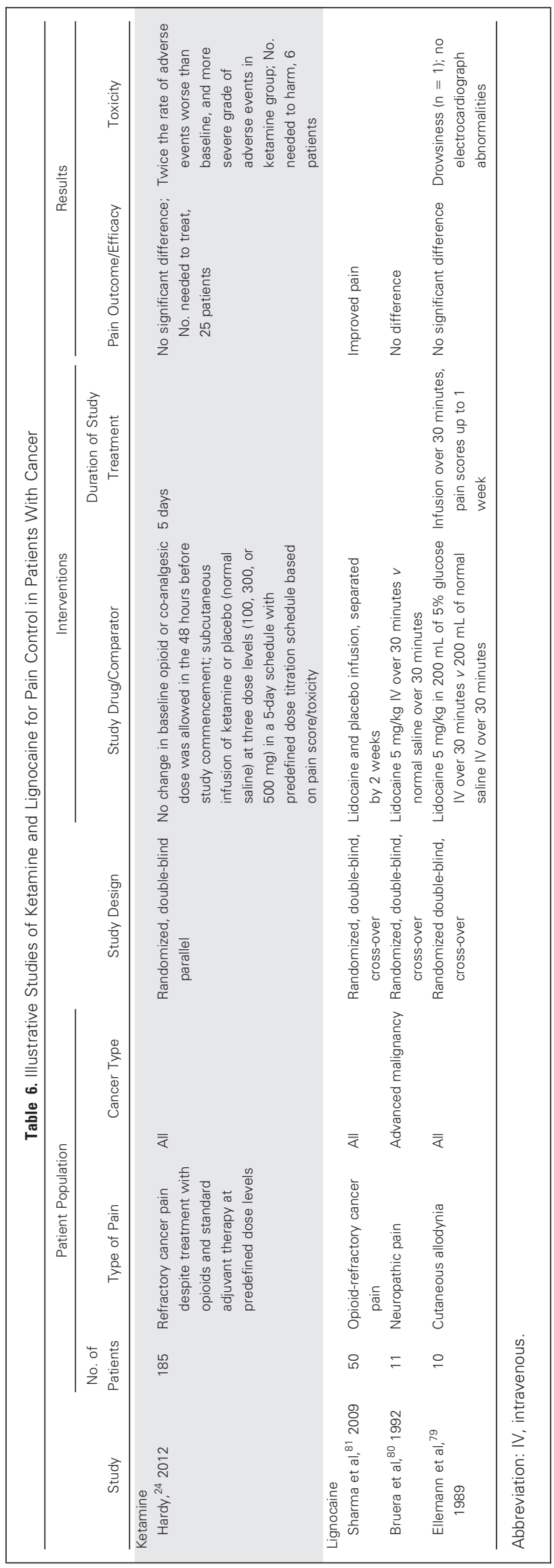




\section{LIMITATIONS OF CURRENT DATA}

The evidence for use of nonopioid analgesia in cancer pain remains limited. With the exception of the bisphosphonate/denosumab trials, most studies have small sample sizes, frequently have methodologic limitations, and lack long-term follow-up, so that data on the effects of chronic use of most of the agents remain limited.

\section{RECOMMENDATIONS FOR FUTURE RESEARCH}

Some of the outstanding questions include the following: whether acetaminophen should be used concurrently with an opioid and, if so, in what dose; whether NSAIDs and corticosteroids can be safely continued long term in patients with cancer and the safety and efficacy of the selective COX-2 inhibitors still on the market; and which nonopi- oid analgesics are best for specific types of pain and in which combinations. Pharmacogenomics and phase IV studies may have a role to play in answering these questions.

\section{AUTHORS' DISCLOSURES OF POTENTIAL CONFLICTS OF INTEREST}

The author(s) indicated no potential conflicts of interest.

\section{AUTHOR CONTRIBUTIONS}

\author{
Conception and design: All authors \\ Collection and assembly of data: All authors \\ Data analysis and interpretation: All authors \\ Manuscript writing: All authors \\ Final approval of manuscript: All authors
}

\section{REFERENCES}

1. Breivik H, Cherny $N$, Collett $B$, et al: Cancerrelated pain: A pan-European survey of prevalence, treatment, and patient attitudes. Ann Oncol 20: 1420-1433, 2009

2. Goudas LC, Bloch R, Gialeli-Goudas $M$, et al: The epidemiology of cancer pain. Cancer Invest 23:182-190, 2005

3. van den Beuken-van Everdingen $\mathrm{MH}$, de Rijke JM, Kessels AG, et al: Prevalence of pain in patients with cancer: A systematic review of the past 40 years. Ann Oncol 18:1437-1449, 2007

4. Apolone G, Bertetto O, Caraceni $A$, et al: Pain in cancer: An outcome research project to evaluate the epidemiology, the quality and the effects of pain treatment in cancer patients. Health Qual Life Outcomes 4:7, 2006

5. Deandrea S, Montanari M, Moja L, et al: Prevalence of undertreatment in cancer pain: $A$ review of published literature. Ann Oncol 19:19851991, 2008

6. WHO: World Health Organization Cancer Pain Relief, With a Guide to Opioid Availability (ed 2). Geneva, Switzerland, World Health Organization, 1996

7. Camu F, Vanlersberghe C: Pharmacology of systemic analgesics. Best Pract Res Clin Anaesthesiol 16:475-488, 2002

8. Mercadante S: Emerging drugs for cancerrelated pain. Support Care Cancer 19:1887-1893, 2011

9. Azevedo São Leão Ferreira $K$, Kimura $M$, Jacobsen Teixeira M: The WHO analgesic ladder for cancer pain control, twenty years of use: How much pain relief does one get from using it? Support Care Cancer 14:1086-1093, 2006

10. Ventafridda $V$, Tamburini $M$, Caraceni $A$, et al: A validation study of the $\mathrm{WHO}$ method for cancer pain relief. Cancer 59:850-856, 1987

11. Zech DF, Grond S, Lynch J, et al: Validation of World Health Organization Guidelines for cancer pain relief: A 10-year prospective study. Pain 63:6576, 1995

12. Rodriguez RF, Castillo JM, Del Pilar Castillo $\mathrm{M}$, et al: Codeine/acetaminophen and hydrocodone/ acetaminophen combination tablets for the management of chronic cancer pain in adults: A 23-day, prospective, double-blind, randomized, parallel-group study. Clin Ther 29:581-587, 2007
13. Zhang $\mathrm{Q}$, Bal-dit-Sollier $\mathrm{C}$, Drouet $\mathrm{L}$, et al: Interaction between acetaminophen and warfarin in adults receiving long-term oral anticoagulants: $A$ randomized controlled trial. Eur J Clin Pharmacol 67:309-314, 2011

14. Paunescu $H$, Coman $O A$, Coman $L$, et al: Cannabinoid system and cyclooxygenases inhibitors. J Med Life 4:11-20, 2011

15. Liu $Y$, Ramírez J, Ratain MJ: Inhibition of paracetamol glucuronidation by tyrosine kinase inhibitors. Br J Clin Pharmacol 71:917-920, 2011

16. Carson JL, Willett LR: Toxicity of nonsteroidal anti-inflammatory drugs: An overview of the epidemiological evidence. Drugs 46:243-248, 1993 (suppl 1)

17. Leppert $W$, Buss $T$ : The role of corticosteroids in the treatment of pain in cancer patients. Curr Pain Headache Rep 16:307-313, 2012

18. Paulsen $\varnothing$, Aass $N$, Kaasa $S$, et al: Do corticosteroids provide analgesic effects in cancer patients? A systematic literature review. J Pain Symptom Manage 46:96-105, 2013

19. Shih A: Role of corticosteroids in palliative care. J Pain Palliat Care Pharmacother 21:69-76, 2007

20. Bennett MI: Effectiveness of antiepileptic or antidepressant drugs when added to opioids for cancer pain: Systematic review. Palliat Med 25:553559, 2011

21. Vadalouca A, Raptis E, Moka E, et al: Pharmacological treatment of neuropathic cancer pain: A comprehensive review of the current literature. Pain Pract 212:219-251, 2012

22. Fallon $\mathrm{MT}$ : Neuropathic pain in cancer. $\mathrm{Br} J$ Anaesth 111:105-111, 2013

23. Jones $\mathrm{DH}$, Nakashima $\mathrm{T}$, Sanchez $\mathrm{OH}$, et al: Regulation of cancer cell migration and bone metastasis by RANKL. Nature 440:692-696, 2006

24. Hardy J, Quinn S, Fazekas B, et al: Randomized, double-blind, placebo-controlled study to assess the efficacy and toxicity of subcutaneous ketamine in the management of cancer pain. J Clin Oncol 30:3611-3617, 2012

25. Doyle D, Hanks GWC, MacDonald N: Oxford Textbook of Palliative Medicine (ed 2). New York, NY, Oxford University Press, 1998

26. Lee WM: Drug-induced hepatotoxicity. N Engl J Med 349:474-485, 2003

27. Axelsson B, Borup $S$ : Is there an additive analgesic effect of paracetamol at step 3? A double- blind randomized controlled study. Palliat Med 17: 724-725, 2003

28. Stockler M, Vardy J, Pillai A, et al: Acetaminophen (paracetamol) improves pain and well-being in people with advanced cancer already receiving a strong opioid regimen: A randomized, double-blind, placebo-controlled cross-over trial. J Clin Oncol 22: 3389-3394, 2004

29. Tasmacioglu B, Aydinli I, Keskinbora K, et al: Effect of intravenous administration of paracetamol on morphine consumption in cancer pain control. Support Care Cancer 17:1475-1481, 2009

30. Cubero DI, del Giglio A: Early switching from morphine to methadone is not improved by acetaminophen in the analgesia of oncologic patients: A prospective, randomized, double-blind, placebocontrolled study. Support Care Cancer 18:235-242, 2010

31. Israel FJ, Parker G, Charles M, et al: Lack of benefit from paracetamol (acetaminophen) for palliative cancer patients requiring high-dose strong opioids: A randomized, double-blind, placebocontrolled, crossover trial. J Pain Symptom Manage 39:548-554, 2010

32. Sima L, Fang WX, Wu XM, et al: Efficacy of oxycodone/paracetamol for patients with bonecancer pain: A multicenter, randomized, doubleblinded, placebo-controlled trial. J Clin Pharm Ther 37:27-31, 2012

33. Toms L, McQuay HJ, Derry $S$, et al: Single dose oral paracetamol (acetaminophen) for postoperative pain in adults. Cochrane Database Syst Rev 4:CD004602, 2008

34. McQuay HJ, Edwards JE, Moore RA: Evaluating analgesia: The challenges. Am J Ther 9:179-187, 2002

35. McQuay HJ, Moore RA: Dose-response in direct comparisons of different doses of aspirin, ibuprofen and paracetamol (acetaminophen) in analgesic studies. $\mathrm{Br} \mathrm{J}$ Clin Pharmacol 63:271278, 2007

36. Gaskell H, Derry S, Moore RA, et al: Single dose oral oxycodone and oxycodone plus paracetamol (acetaminophen) for acute postoperative pain in adults. Cochrane Database Syst Rev 3:CD002763, 2009

37. Caraceni A, Hanks G, Kaasa S, et al: Use of opioid analgesics in the treatment of cancer pain: Evidence-based recommendations from the EAPC. Lancet Oncol 13:e58-e68, 2012 
38. Nabal M, Librada S, Redondo MJ, et al: The role of paracetamol and nonsteroidal anti-inflammatory drugs in addition to WHO Step III opioids in the control of pain in advanced cancer: A systematic review of the literature. Palliat Med 26:305-312, 2012

39. Radbruch L, Elsner F: Emerging analgesics in cancer pain management. Expert Opin Emerg Drugs 10:151-171, 2005

40. Warner TD, Mitchell JA: Cyclooxygenases: New forms, new inhibitors, and lessons from the clinic. FASEB J 18:790-804, 2004

41. Rostom A, Muir K, Dubé $C$, et al: Gastrointestinal safety of cyclooxygenase-2 inhibitors: A Cochrane Collaboration systematic review. Clin Gastroenterol Hepatol 5:818-828, 2007

42. Lanza FL, Chan FK, Quigley EM: Guidelines for prevention of NSAID-related ulcer complications. Am J Gastroenterol 104:728-738, 2009

43. Madigan D, Sigelman DW, Mayer JW, et al: Under-reporting of cardiovascular events in the rofecoxib Alzheimer disease studies. Am Heart $J$ 164:186-193, 2012

44. Baron JA, Sandler RS, Bresalier RS, et al: Cardiovascular events associated with rofecoxib: Final analysis of the APPROVe trial. Lancet 372 : 1756-1764, 2008

45. Sunshine A, Olson NZ: Analgesic efficacy of ketoprofen in postpartum, general surgery, and chronic cancer pain. J Clin Pharmacol 28:S47-S54, 1988

46. Eisenberg E, Berkey CS, Carr DB, et al: Efficacy and safety of nonsteroidal antiinflammatory drugs for cancer pain: A meta-analysis. J Clin Oncol 12:2756-2765, 1994

47. Ferrer-Brechner T, Ganz P: Combination therapy with ibuprofen and methadone for chronic cancer pain. Am J Med 77:78-83, 1984

48. Lomen $\mathrm{PL}$, Samal $\mathrm{BA}$, Lamborn $\mathrm{KR}$, et al: Flurbiprofen for the treatment of bone pain in patients with metastatic breast cancer. Am J Med 80:83-87, 1986

49. Stambaugh J, Drew J: A double-blind parallel evaluation of the efficacy and safety of a single dose of ketoprofen in cancer pain. J Clin Pharmacol 28:S34-S49, 1988

50. Staquet MJ: A double-blind study with placebo control of intramuscular ketorolac tromethamine in the treatment of cancer pain. J Clin Pharmacol 29:1031-1036, 1989

51. Carlson RW, Borrison RA, Sher HB, et al: A multiinstitutional evaluation of the analgesic efficacy and safety of ketorolac tromethamine, acetaminophen plus codeine, and placebo in cancer pain Pharmacotherapy 10:211-216, 1990

52. Johnson JR, Miller AJ: The efficacy of choline magnesium trisalicylate (CMT) in the management of metastatic bone pain: A pilot study. Palliat Med 8:129-135, 1994

53. Mercadante $S$, Fulfaro F, Casuccio A: A randomised controlled study on the use of antiinflammatory drugs in patients with cancer pain on morphine therapy: Effects on dose-escalation and a pharmacoeconomic analysis. Eur J Cancer 38:13581363, 2002
54. McNicol E, Strassels SA, Goudas $L$, et al: NSAIDS or paracetamol, alone or combined with opioids, for cancer pain. Cochrane Database Syst Rev 1:CD005180, 2005

55. Stambaugh J: Analgesic efficacy, safety and acceptability of zomepirac sodium in comparison to morphine sulfate in the treatment of pain secondary to malignancy. Curr Ther Res 31:922-929, 1982

56. Tonachella R, Curcio C, Grossi E: Diclofenac sodium in cancer pain: A double-blind withinpatients comparison with pentazocine. Curr Ther Res 37:1130-1133, 1985

57. Staquet M, Renaud A: Double-blind, randomized trial of piroxicam and codeine in cancer pain Curr Ther Res 53:435-439, 1993

58. Duarte Souza JF, Lajolo PP, Pinczowski $\mathrm{H}$, et al: Adjunct dipyrone in association with oral morphine for cancer-related pain: The sooner the better. Support Care Cancer 15:1319-1323, 2007

58a. Weingart WA Sorkness $\mathrm{CA}$, Earhart $\mathrm{RH}$ Analgesia with oral narcotics and added ibuprofen in cancer patients. Clin Pharm 4:53-58, 1985

59. Bjorkman R, Ullman A, Hedner J: Morphinesparing effect of diclofenac in cancer pain. Eur $\mathrm{J}$ Clin Pharmacol 44:1-5, 1993

60. Feuer DJ, Broadley KE: Corticosteroids for the resolution of malignant bowel obstruction in advanced gynaecological and gastrointestinal cancer. Cochrane Database Syst Rev 2:CD001219, 2000

61. Vecht CJ, Hovestadt A, Verbiest HB, et al: Dose-effect relationship of dexamethasone on Karnofsky performance in metastatic brain tumors: A randomized study of doses of 4,8 , and $16 \mathrm{mg}$ per day. Neurology 44:675-680, 1994

62. Bruera $E$, Roca $E$, Cedaro $L$, et al: Action of oral methylprednisolone in terminal cancer patients: A prospective randomized double-blind study. Cancer Treat Rep 69:751-754, 1985

63. Bruera E, Moyano JR, Sala R, et al: Dexamethasone in addition to metoclopramide for chronic nausea in patients with advanced cancer: A randomized controlled trial. J Pain Symptom Manage 28: 381-388, 2004

64. Della Cuna GR, Pellegrini A, Piazzi M: Effect of methylprednisolone sodium succinate on quality of life in preterminal cancer patients: A placebocontrolled, multicenter study-The Methylprednisolone Preterminal Cancer Study Group. Eur J Cancer Clin Oncol 25:1817-1821, 1989

65. Popiela T, Lucchi R, Giongo F: Methylprednisolone as palliative therapy for female terminal cancer patients: The Methylprednisolone Female Preterminal Cancer Study Group. Eur J Cancer Clin Oncol 25:1823-1829, 1989

66. Beydoun A, Backonja M: Mechanistic stratification of antineuralgic agents. J Pain Symptom Manage 25:S18-S30, 2003

67. Jongen $J L$, Huijsman $M L$, Jessurun $J$, et al: The evidence for pharmacologic treatment of neuropathic cancer pain: Beneficial and adverse effects. J Pain Symptom Manage 46:581-590, 2013

68. Rao RD, Michalak JC, Sloan JA, et al: Efficacy of gabapentin in the management of chemotherapyinduced peripheral neuropathy: A phase 3 random- ized, double-blind, placebo-controlled, crossover trial (N00C3). Cancer 110:2110-2118, 2007

69. Smith EM, Pang $\mathrm{H}$, Cirrincione $\mathrm{C}$, et al: Effect of duloxetine on pain, function, and quality of life among patients with chemotherapy-induced painful peripheral neuropathy: A randomized clinical trial. JAMA 309:1359-1367, 2013

70. Lipton A, Theriault RL, Hortobagyi GN, et al: Pamidronate prevents skeletal complications and is effective palliative treatment in women with breast carcinoma and osteolytic bone metastases: Long term follow-up of two randomized, placebocontrolled trials. Cancer 88:1082-1090, 2000

71. Body JJ, Diel IJ, Bell R, et al: Oral ibandronate improves bone pain and preserves quality of life in patients with skeletal metastases due to breast cancer. Pain 111:306-312, 2004

72. Saad F, Eastham J: Zoledronic acid improves clinical outcomes when administered before onset of bone pain in patients with prostate cancer. Urology 76:1175-1181, 2010

73. Cleeland CS, Body JJ, Stopeck A, et al: Pain outcomes in patients with advanced breast cancer and bone metastases: Results from a randomized, double-blind study of denosumab and zoledronic acid. Cancer 119:832-838, 2013

74. Wong MH, Stockler MR, Pavlakis N: Bisphosphonates and other bone agents for breast cancer. Cochrane Database Syst Rev 2:CD003474, 2012

75. Yuen KK, Shelley M, Sze WM, et al: Bisphosphonates for advanced prostate cancer. Cochrane Database Syst Rev 4:CD006250, 2006

76. Mhaskar R, Redzepovic J, Wheatley $K$, et al: Bisphosphonates in multiple myeloma: A network metaanalysis. Cochrane Database Syst Rev 5:CD003188, 2012

77. Peddi P, Lopez-Olivo MA, Pratt GF, et al: Denosumab in patients with cancer and skeletal metastases: A systematic review and metaanalysis. Cancer Treat Rev 39:97-104, 2013

78. Henry DH, Costa L, Goldwasser F, et al: Randomized, double-blind study of denosumab versus zoledronic acid in the treatment of bone metastases in patients with advanced cancer (excluding breast and prostate cancer) or multiple myeloma. J Clin Oncol 29:1125-1132, 2011

79. Ellemann $K$, Sjögren $P$, Banning $A M$, et al: Trial of intravenous lidocaine on painful neuropathy in cancer patients. Clin J Pain 5:291-294, 1989

80. Bruera E, Ripamonti C, Brenneis C, et al: A randomized double-blind crossover trial of intravenous lidocaine in the treatment of neuropathic cancer pain. J Pain Symptom Manage 7:138-140, 1992

81. Sharma S, Rajagopal MR, Palat G, et al: A phase II pilot study to evaluate use of intravenous lidocaine for opioid-refractory pain in cancer patients. J Pain Symptom Manage 37:85-93, 2009

82. Bowles DW, O'Bryant CL, Camidge DR, et al: The intersection between cannabis and cancer in the United States. Crit Rev Oncol Hematol 83:1-10, 2012 